\title{
Scenario of Tubercular Lymphadenitis in a Tertiary Health Care Centre of Assam
}

\author{
Mondita Borgohain 1 , Banasmita Baruah ${ }^{2}$ \\ 1Professor, ${ }^{\star}$ Post Graduate Trainee, \\ Department of Pathology, Assam Medical College, Dibrugarh, Assam, India.
}

\begin{abstract}
Introduction: Tubercular lymphadenitis is the most common extrapulmonary manifestation of tuberculosis. Clinical suspiciousness can help to arrive at the diagnosis. Fine needle aspiration cytology is usually done to make a definitive diagnosis. The present study was conducted to evaluate the scenario of tuberculosis among the cases of lymphadenopathy presenting within 1 year at a tertiary health care centre in the north east region of India.

Materials and Methods: The present prospective hospital based study was carried out on 586 consecutive cases attending the cytology section of the department of pathology, Assam Medical College, Dibrugarh from January'14 to December'14. After clinical examination consecutive superficial lymph nodes were aspirated and subjected to cytological evaluation. In all the cases alcohol fixed and air dried smears were subjected to cytological evaluation with hematoxylin and eosin, MGG and Ziehl neelsen (ZN) staining. Various clinical aspects and cytomorphological presentations were studied thereafter.

Results: Out of 586 cases studied 168 cases came out to be positive for acid fast bacilli on ZN staining, 94 cases were granulomatous lesion, 176 cases were found to be reactive and 148 were metastatic .Higher incidence has been seen in the age group of 11-30 years and among the female
\end{abstract}

\section{INTRODUCTION}

Tuberculosis is a serious chronic pulmonary and systemic disease caused most often caused by Mycobacterium tuberculosis. The source of transmission is man with active tuberculosis. Lymphadenitis is the most frequent presentation of extrapulmonary Tuberculosis, usually occurring in the cervical region (Scrofula). In HIV positive cases have multifocal disease, systemic symptoms and either pulmonary or other organ involvement by active tuberculosis. It remains both diagnostic and therapeutic challenge in some cases. As it mimics other pathological processes and yields inconsistent findings.

The classic term Scrofula was derived from the latin word meaning glandular swelling. It was mentioned by Hippocrates (460- 377 BC) in his writings. The European Kings of the middle ages referred to it as the "King of the evil".

According to the WHO, nearly 8.7 million new cases and 1.4 population. Tuberculosis forms the $2^{\text {nd }}$ most common etiology of lymphadenopathy cases preceded by reactive lymphadenitis. Only necrosis without epithelioid cell granuloma was the most common cytological picture.

Conclusion: The study concludes that tuberculosis forms one of the most common infectious diseases in rural areas of Assam.

Key Words: Assam, Tubercular lymphadenitis, Fine needle aspiration cytology, ZN stain, Acid fast bacilli.

\section{${ }^{*}$ Correspondence to:}

Dr.Banasmita Baruah

Department of Pathology

Basic science Building

Assam Medical College ,Dibrugarh, Assam.

Article History:

Received: 22-10-2016, Revised: 09-11-2016, Accepted: 19-11-2016

\begin{tabular}{|l|c|}
\hline \multicolumn{2}{|c|}{ Access this article online } \\
\hline Website: & Quick Response code \\
www.ijmrp.com & \\
\hline DOI: & \\
10.21276/ijmrp.2016.2.6.011 & \\
\hline
\end{tabular}

million deaths worldwide every year. In India 2 million develop active disease and about half a million die with this disease. TB lymphadenitis is seen in $35 \%$ of extrapulmonary TB which constitutes 15 to $20 \%$ of all cases. In HIV positive patients TB lymphadenitis account for $53-62 \%$.

Cervical lymph nodes are the most common sites in $60 \%$ to $90 \%$ patients with or without involvement of other lymphoid tissue. Mostly seen in the second decade but the disease can affect any age while females are more prone. Racial and ethnic minorities, foreign born black and Asians more likely to suffer than the whites. The present study is undertaken to analyze the scenario of tuberculosis among the cases of lymphadenitis presenting in a tertiary health care centre. The aims and objective of the study is to evaluate the cytomorphology with acid fast stain as a valuable tool for diagnosing Tubercular lymphadenitis. 


\section{MATERIALS AND METHODS}

Study Design: A hospital -based prospective study.

Place: Assam Medical College, Department of Pathology

Duration: 1 year

Inclusion criteria: Patients with clinical features consistent with tuberculosis, above the age group of one year were considered for the study.

Exclusion criteria: Reactive and metastatic lymphadenitis and children below 1 year of age were excluded from the study.

This study was carried out in the cytology section of the pathology department of Assam medical college Dibrugarh during the period from January to December, 2014.

The OPD and IPD patients attending the cytology section as advised by the clinicians in clinically suspected cases of TB (eg. With complaints like rise of temperature, weight loss, positive contact history of tuberculosis, enlarged solitary /multiple lymph nodes etc.) were considered for the study. A detailed clinical history of the patient was taken. The demographic data and medical history were taken from each patient including age, gender, socioeconomic status, presence of other risk factors, contact history of tuberculosis etc. After a detailed clinical examination of the node they were aspirated using most preferably $25 \mathrm{G}$ disposable needle. The area was disinfected prior to aspiration. The aspirated material was spread evenly on clean and grease free slide. In all the cases air dried and alcohol fixed smears were made and stained with MGG (air dried), $\mathrm{H}$ and $\mathrm{E}$ (alcohol fixed) and Z\&N (air dried) stain. Additional unstained slides were kept.

\section{RESULTS}

During this period a total of 586 no of cases were studied. Amongst them Tubercular and granulomatous comprised the largest group.

Maximum incidence was seen in the age group of 21-30 yrs. The youngest patient was a $1 \mathrm{yr} 5$ months male child and the eldest were a male and female patient of 84yrs. Females were more prone to tubercular lymphadenitis in our study.

Of the 262 cases studied 168 showed positivity for AFB. The rest 94 cases were negative for AFB.

Table 1: Incidence of different types of adenopathy in Males and Females

\begin{tabular}{lccc}
\hline Diagnosis & Male & Female & Total \\
\hline Tubercular & 53 & 115 & 168 \\
Granulomatous & 40 & 54 & 94 \\
Reactive & 76 & 100 & 176 \\
Metastasis & 90 & 58 & 148 \\
\hline
\end{tabular}

Table 2: Incidence of Tubercular Lymphadenopathy in relation to age and sex

\begin{tabular}{lcccc}
\hline Age Group & Male & Female & Total & $\%$ \\
\hline 1-10 Yrs. & 7 & 8 & 15 & 8.9 \\
11-20 Yrs. & 15 & 39 & 54 & 32.1 \\
21-30 Yrs. & 10 & 45 & 55 & 32.7 \\
31-40 Yrs. & 12 & 13 & 25 & 14.9 \\
41-50 Yrs. & 6 & 6 & 12 & 7.2 \\
>50 Yrs. & 3 & 4 & 7 & 4.2 \\
\hline
\end{tabular}

Fig 1: Incidence of Tubercular Lymphadenopathy in relation to age and sex

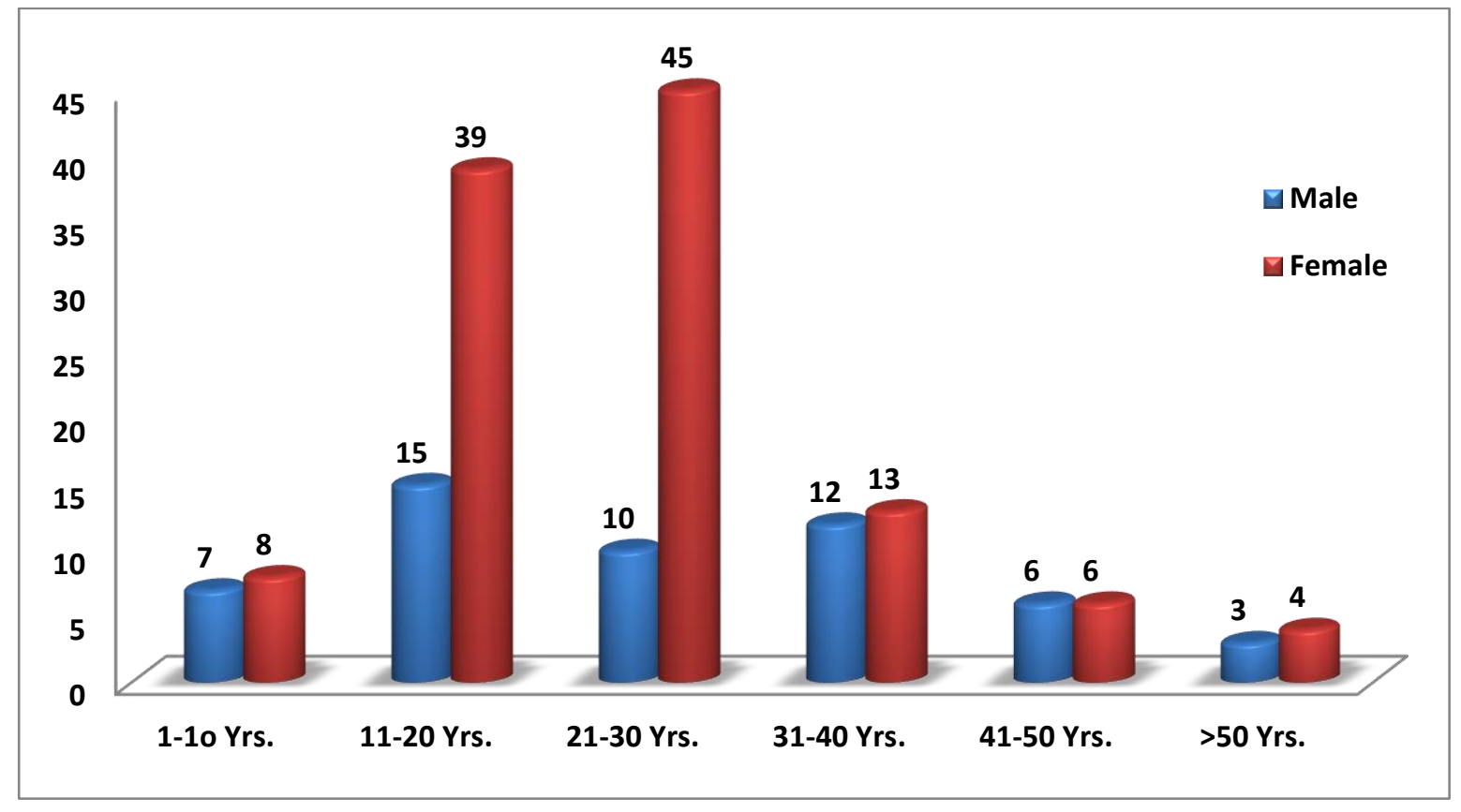



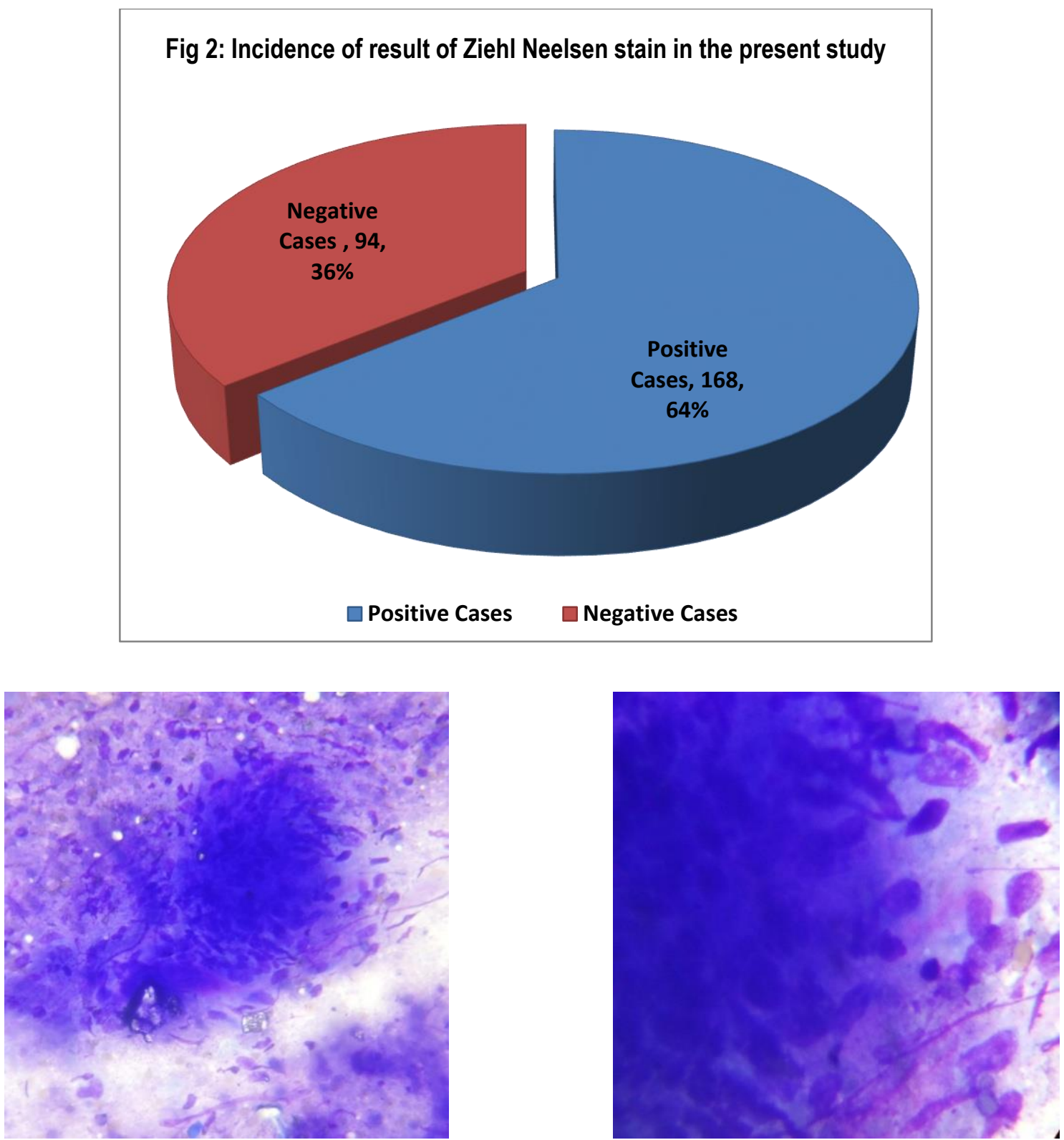

Fig 3: Photomicrograph Of An Epithelioid Granuloma (FNAC)
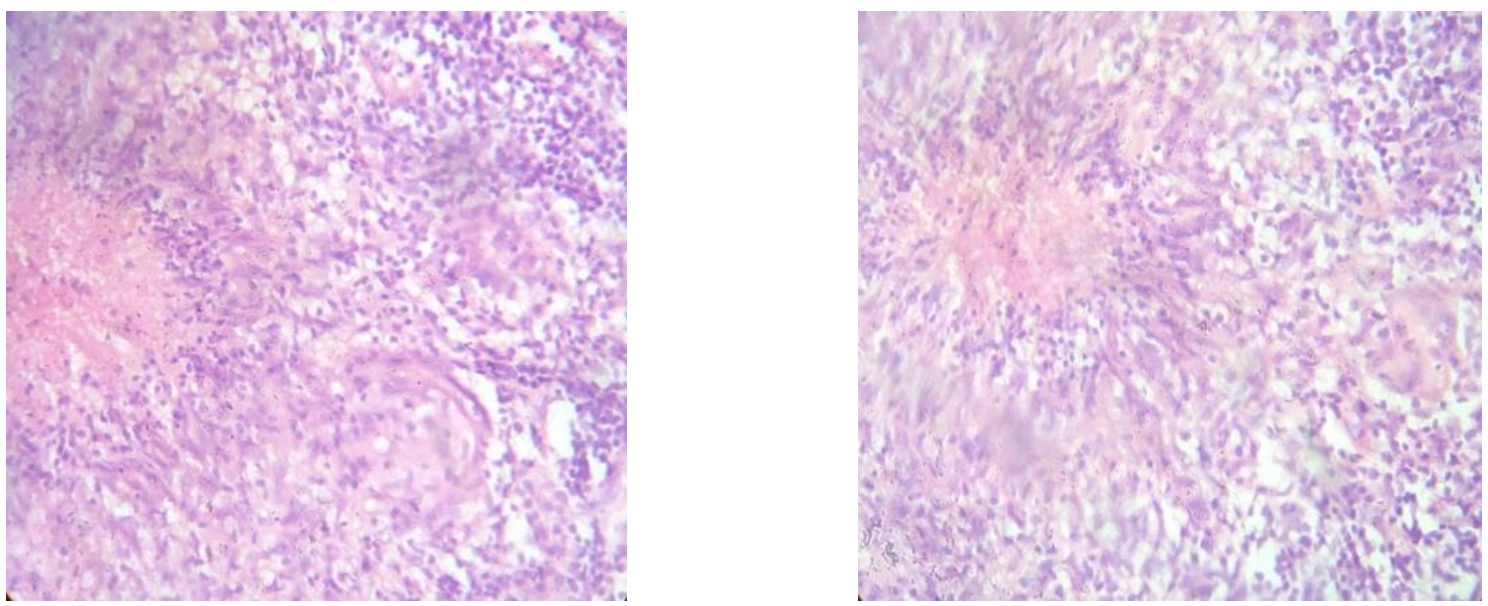

Fig 4: Photomicrograph Of A Tubercular Granuloma (HPE)

\section{DISCUSSION}

Tuberculosis is one of the commonly found chronic pulmonary and extrapulmonary disease in developing countries like India.

In our present study, maximum incidence of tubercular lymphadenitis was observed in the age group of 21 to 30 years. Similar observations were reported by Kumar $\mathrm{H}$ et al., 2013;1
Laishram RS et al., 2012; ${ }^{2}$ and Dowerah et al., 2015. ${ }^{3}$ However a declining trend was seen in the elderly population which was relevant with the findings of Ahmad et al. ${ }^{4}$ Rajashekaran et al. ${ }^{5}$ have shown that no age group was exempted from tubercular lymphadenitis which was also true in our study. 
A female preponderance has been noticed in our study. Similar findings were shown by Pamra et al., ${ }^{6}$ Ergete and Bekele ${ }^{7}$, Nidhi P et al. ${ }^{8}$ and Purohit et al. ${ }^{9}$ While Laishram et al. ${ }^{2}$ and Poudel et al. ${ }^{10}$ have described a male preponderance of the cases.

In our present study, Ziehl Neelsen stain for Acid Fast Bacilli (AFB) on Fine Needle Aspiration smear showed AFB positivity to be $64 \%$. Varying ranges of AFB positivity incidences has been described by many authors. Similar studies by Nidhi P et al.,20118 found AFB positivity to be $71 \%$ while Kumar $\mathrm{H}$ et al.,2013;1 and Thakur B et al.,2013;11 found AFB positivity in $35.57 \%$ and $26.67 \%$ respectively. In our study tubercular lymphadenopathy with 168 no. of cases (28.67\%) was the second most common cause of peripheral Lymphadenopathy, reactive lymphadenopathy with $176(30.03 \%)$ cases being the commonest one. Reddy MP et al. ${ }^{12}$ also noted similar findings.

Clinically in our study cervical region was the most commonly affected region, involving about $95 \%$ of the cases. This was in concordance with Bezabith et al. $^{13}$ who observed cervical involvement in $74.2 \%$ of cases. A study conducted by Sharma et al. ${ }^{14}$ showed similar results with female predominance and most common involvement of cervical region (88.2\%).

Again the most common cytological picture evident in our study was that of necrosis without epithelioid granulomas in $64 \%$ of the cases which was consistent with the findings of Nidhi $P$ et al. ${ }^{8}$ also showed similar picture. While in a study by Gupta et al. ${ }^{15}$ epithelioid clusters with or without langhans giant cell with necrosis was the most commonly observed cytological pattern in $50.35 \%$.

\section{CONCLUSION}

Tuberculosis has become one of the major health problems at present. In our setup also, being a referral centre, a very high no of cases are detected annually. In the rural areas of Assam poverty and household overcrowding appeared to be some of the most important and frequently noticed risk factors among the patients. Incomplete antitubercular treatment in a previously diagnosed pulmonary tuberculosis case was another common factor.

The diagnosis needs a high index of suspicion and the application of a variety of diagnostic modalities. FNAC coupled with ZN stained smear study is a highly specific tool to report a definite diagnosis of tubercular lymphadenitis.

However diagnostic accuracy can further be enhanced by culture of the material and PCR study.

Tubercular lymphadenitis is best treated with antitubercular medications except in a few cases where surgical intervention is required. The disease burden can be reduced if an early diagnosis can be made and a complete course of treatment is ensured thereafter.

\section{SOURCE OF SUPPORT}

Cytology section, Department of Pathology, Assam Medical College, Dibrugarh, Assam, India.

\section{REFERENCES}

1. Kumar H, Chandanwale SS, Gore CR, Buch AC, Satav VH, Pagaro PM: Role of fine needle aspiration cytology in assessment of cervical lymphadenopathy. Med J DY Patiluniv 2013;6:400-4.
2. Laishram RS, Devi RKB, Konjengbam R, Devi RKT, Sharma LDC;Journal Indian Academy of clinical Medicine 2010;11(1):31-5. 3. Ena Dowerah, Upakul Kashyap. Value of FNAC in the diagnosis of tubercular lymphadenitis, The Clarion Volume 4 Number 2 (2015).

4. Ahmad SS, Akhtar S, Akhtar K, Naseem S, Mansoor T, Khalil S. Incidence of tuberculosis from study of fine needle aspiration cytology in lymphadenopathy and acid fast staining. Ind $\mathrm{J}$ Community Medicine 2005; 30(2):63-5.

5. Rajsekaran S, Gunasekaran M, Bhanumati V. Tuberculous cervical lymphadenitis in HIV positive and negative patients. Indian J Tuberc2001; 48: 201-4.

6. Pamra S, Baily GVS, Gupta $S$ et al. Cervical lymphadenopathies. Indian J Tuberc 1987; 96-100.

7. Ergete $W$ and Bekele $A$. Acid fast bacilli in aspiration smears from tuberculous patients. Ethiop J Health Dev 2000;14(1):99-104. 8. Nidhi P, Sapna T, Shalini M, Kumud G: FNAC in tuberculous lymphadenitis: experience from a tertiary level referral centre. Indian J Tuberc 2011 jul:58(3):102-7.

9. Purohit MR, Mustafa T, Morkve O, Sviland L. Gender differences in the clinical diagnosis of tuberculous lymphadenitis-a hospital based study from central India. International Journal of Infectious diseases 2009 Sep;13(5):600-05.

10. Poudel A, Jain S K: Fine Needle Aspiration Cytology: A tool for early diagnosis of cervical lymph node lesions. Journal of Universal College of Medical sciences 2014; Volume 2,No 4.

11. Thakur B, Mehrotra R, Nigam J S; Correlation of various techniques in diagnosis of tuberculous lymphadenitis on fine needle aspiration cytology: Pathology Research International Volume 2013(2013),article ID 824620,4 pages.

12. Reddy MP, Moorchung N, ChoudhuryA. Clinicopathological profile of pediatric lymphadenopathy. Indian J pediatr 2002; 69:1047-51.

13. Bezabith M, Marium DW, Selassie SG. Fine needle aspiration cytology of suspected tuberculous lymphadenitis. Cytopathology 2002; 13(5): 284-90.

14. Sharma S, Sarin R, Khalid UK, Singla N, Sharma PP, Behera D. Clinical profile and treatment outcome of tuberculous lymphadenitis in children using DOTS strategy. Indian J Tuberc 2010;57 :4-11.

15. Gupta AK, Nayar M, Chandra M. Critical appraisal of fine needle aspiration cytology in tuberculous lymphadenitis. Acta Cytol. 1992 May-Jun;36(3):391-4

\section{Conflict of Interest: None Declared.}

Copyright: (c) the author(s) and publisher. IJMRP is an official publication of Ibn Sina Academy of Medieval Medicine \& Sciences, registered in 2001 under Indian Trusts Act, 1882.

This is an open access article distributed under the terms of the Creative Commons Attribution Non-commercial License, which permits unrestricted non-commercial use, distribution, and reproduction in any medium, provided the original work is properly cited.

Cite this article as: Mondita Borgohain, Banasmita Baruah. Scenario of Tubercular Lymphadenitis in a Tertiary Health Care Centre of Assam. Int J Med Res Prof. 2016; 2(6):63-66. DOI:10.21276/ijmrp.2016.2.6.011 